\title{
Experimental Electrochemical Capacitor Test Results
}$$
\text { CONF- } 97 / 212--
$$ \\ R. B. Wright, T. C. Murphy, and W. E. Kramer \\ Idaho National Engineering and Environmental Laboratory \\ P.O. Box 1625 \\ Idaho Falls, ID 83415-3830 \\ e-mail Address: rbw2@inel.gov \\ and \\ R. A. Sutula and S. A. Rogers \\ U. S. Department of Energy \\ Washington, D. C. 20585
}

\begin{abstract}
Various electrochemical capacitors (ultracapacitors) are being developed for hybrid vehicles as candidate power assist devices for the fast response engine. The primary functions of the ultracapacitor are to level the dynamic power loads on the primary propulsion device and recover available energy from regenerative breaking during off-peak power periods. Ultracapacitors show promise toward being able to accept high regenerative pulses while exhibiting very high cycle life. This paper will present test data from selected U.S. Department of Energy (DOE) supported ultracapacitor projects designed to meet the fast response engine requirements. Devices containing carbon, conducting polymers, and metal oxide electrode materials in combination with aqueous or organic electrolytes are being supported by the DOE. This paper will present and discuss testing data obtained from recent prototype capacitors supplied by Maxwell Energy Products, Inc., SAFT America, Inc., Federal Fabrics-Fibers and the University of Wisconsin-Madison. Constant-current, constant-power, leakage-current, and self-discharge testing of these various capacitors have been conducted. All devices were cycled between the rated charged voltage and zero volts for the constant-current tests and between the rated charged voltage and half that value for the constant-power tests.
\end{abstract}

\section{Background}

A number of highly promising materials have been studied for use as electrochemical capacitor electrodes that utilize both Faradaic and non-Faradaic processes for charge separation and storage. These include carbon, doped conducting polymers, metal oxides, and non-oxide ceramics in conjunction with aqueous and non-aqueous electrolytes. In 1991 the U.S. Department of Energy (DOE) established a program to develop electrochemical capacitors. ${ }^{1}$ Goals for specific energy $(16 \mathrm{Wh} / \mathrm{kg}$ ) and specific power (750 to $1000 \mathrm{~W} / \mathrm{kg})$, and volumetric energy density $(24 \mathrm{Wh} / \mathrm{L})$ were established based on the year 2004 Partnership for a New Generation of Vehicles (PNGV) fast response engine requirements. Identified elsewhere are the major contributors to the program that have included national laboratories, universities, and private industry. ${ }^{2}$ Coordination of the development, testing and evaluation of prototype capacitors is the responsibility of the Idaho National Engineering and Environmental Laboratory (INEEL). This paper describes the test results obtained on prototype capacitors prepared by Maxwell Energy Products, Inc., SAFT 


\section{DISCLAIMER}

This report was prepared as an account of work sponsored by an agency of the United States Government. Neither the United States Government nor any agency thereof, nor any of their employees, makes any warranty, express or implied, or assumes any legal liability or responsibility for the accuracy, completeness, or usefulness of any information, apparatus, product, or process disclosed, or represents that its use would not infringe privately owned rights. Reference herein to any specific commercial product, process, or service by trade name, trademark, manufacturer, or otherwise does not necessarily constitute or imply its endorsement, recommendation, or favoring by the United States Government or any agency thereof. The views and opinions of authors expressed herein do not necessarily state or reflect those of the United States Government or any agency thereof. 
America, Inc., Federal Fabrics-Fibers and the University of Wisconsin-Madison. The devices supplied by these manufactures were tested according to test procedures developed at the INEEL ${ }^{3}$.

\section{Discussion of Test Results}

Three non-aqueous, carbon-based $3 \mathrm{~V}$, nominally rated $155 \mathrm{~F}$ to $165 \mathrm{~F}$ cells, $(25.4$ $\left.\mathrm{cm} \times 7.6 \mathrm{~cm} \times 0.13 \mathrm{~cm} ; 193 \mathrm{~cm}^{2}\right) 0.0251$ liter volume, weighing on average $0.0328 \mathrm{~kg}$ (devices \#1141, \#1142 and \#1143) were fabricated by Maxwell Energy Products, Inc. and tested at the INEEL. These cells displayed near-ideal behavior during constant-current discharge tests in that the voltage decreased in a linear fashion with discharge time during constant-current discharges ranging from $1 \mathrm{~A}$ to $24 \mathrm{~A}$ as is shown in Figure 1 for capacitor \#1143. From the constant-current test data the equivalent series resistances (ESRs) of the capacitors were measured using the "IR-step" method ${ }^{3}$ when the current is suddenly changed at the beginning of the constant-current discharge. Figure 2 plots the ESR values as a function of the constant current discharge used in the tests for the three capacitors of this set. The values varied between 9 to 21 milliohms over the constant-current discharge range of 1 to $24 \mathrm{~A}$. The measured capacitances from data acquired from the constant-current discharge tests (plotted in Figure 3) decreased in a fairly linear fashion as a function of increasing discharge current from $165 \mathrm{~F}$ to $77 \mathrm{~F}$. Representative constant-power discharge data are shown in Figure 4. From these data, the specific energy and specific power were determined. These values are plotted in Figure 5 in the form of a Ragone plot that shows the change in specific energy as a function of power for the three capacitors. The next test was the leakage-current test and the results for capacitors \#1142 and \#1143 are shown in Figure 6. The figure shows the current required to maintain a constant voltage of three volts on the capacitors as a function of test time. The leakage-current is generally thought to arise from charge-transfer reactions at the electrodes and can be modeled as a parallel resistor between the electrodes of the capacitor. The results of the self-discharge test for the three devices is shown in Figure 7 that plots the decrease in the initial capacitor potential, $3 \mathrm{~V}$, as a function of test time after it has been placed in an open-circuit state. The self-discharge test measures the ability of the capacitor to store energy as a function of time after it has been charged to its working voltage: Since the total potential energy stored in a capacitor is equal to $E=$ $1 / 2 \mathrm{CV}(\mathrm{t})^{2}$ where $\mathrm{E}$ is the energy in joules, $\mathrm{C}$ is the capacitance of the capacitor in farads, and $V(t)$ is the voltage on the capacitor at a time $t$ after it has been charged to its initial voltage and left in a open-circuit condition a decrease in the voltage on the capacitor will have a dramatic affect on its total stored energy. Capacitor \#1142 is the "best" capacitor in that after 60 hours it has lost approximately $40 \%$ of its initial stored energy while the "worst" capacitor, \#1141 lost approximately $72 \%$.

Maxwell Energy Products, Inc. also delivered three carbon/non-aqueous devices (\#1021, \#1022 and \#1023) rated at $2300 \mathrm{~F}$ at $2.3 \mathrm{~V}$ with an average weight of $0.63 \mathrm{~kg} .{ }^{4}$ The carbon has an extremely high volumetric surface area that is responsible for the high capacitance of the electrodes. The aluminum matrix is added as a means of reducing the number of carbon/carbon contact points the current must flow through before it reaches the current collecting phase. This decrease in the number of contact points lowers the internal resistance of the capacitor. The aluminum composite structure also minimizes packaging pressure required to achieve the lowest internal resistance in the device. The capacitor housings were constructed of aluminum and had overall dimensions of $13.5 \mathrm{~cm} \mathrm{x} 6 \mathrm{~cm} \mathrm{x} 5.7$ $\mathrm{cm}\left(462 \mathrm{~cm}^{3} ; 0.462\right.$ liters). Constant-current tests were performed with discharges ranging up to $300 \mathrm{~A}$ over a voltage range of $3 \mathrm{~V}$ to $0 \mathrm{~V}$. Representative data from capacitor \#1023 are shown in Figure 8. The voltage decrease is fairly linear with time as would be expected 
from an ideal capacitor model with a capacitor in series with a resistor. From these data the ESR and capacitance values were calculated for each of the three devices and are plotted in Figures 9 and 10 , respectively. The ESR values ranged from 0.5 to 1.5 milliohms at $10 \mathrm{~A}$ decreasing to 0.2 to 0.6 milliohms at $100 \mathrm{~A}$. The capacitance values generally decreased as a function of discharge current and varied from $2370 \mathrm{~F}$ to $2465 \mathrm{~F}$ at $10 \mathrm{~A}$ to $2270 \mathrm{~F}$ to $2420 \mathrm{~F}$ at $300 \mathrm{~A}$. Constant-power tests up to $330 \mathrm{~W}$ were next conducted on the three capacitors; representative data from capacitor \#1023 is shown in Figure 11. Measured values for the specific energy and specific power for the three capacitors are shown in Figure 12. The specific energy decreased in a fairly linear manner with increasing specific power. Leakagecurrent data are shown in Figure 13. Capacitor \#1021 is not very good as its leakage current stabilized at 85 milliamperes after 8 hours while devices \#1022 and \#1023 have leakage currents of approximately 10 milliamperes after $\sim 21$ hours. The self-discharge test data are shown in Figure 14 for the three capacitors. Capacitor $\# 1023$ only looses $22 \%$ of its initial stored energy after 48 hours while capacitor \#1021 looses $~ 77 \%$ of its stored energy after this same period of time. These capacitors (except for \#1021) retain a higher percentage of their stored energy than the previous set (\#1041, \#1042 and \#1043) of Maxwell capacitors.

Electrochemical capacitors in the charged condition, like batteries, are in a state of high energy relative to that of the system in the discharged state. There is, therefore, a driving force corresponding to the free energy of discharge that tends to diminish the charge if some mechanism(s) of self-discharge exist by which that discharge can take place. ${ }^{5,6}$ Selfdischarge of a charged capacitor can only occur if some Faradaic electron-transfer process(es) can take place at and below the maximum potential. An ideal capacitor has no self-discharge or current-leakage pathway and hence can remain charged indefinitely. Practical capacitors, however, like batteries, can suffer self-discharge over a period of time so that this phenomenon is of major interest in the evaluation of capacitor (and battery) performance and does influence the materials and fabrication methods used in their production. Conway ${ }^{5,6}$ has identified three potential causes of self-discharge: (1) overcharging of the capacitor beyond the respective " + " or "-" potential of the electrolyte. The leakage process corresponds to a Faradaic, potential-dependent charge-transfer reaction. An equivalent circuit representation of the behavior of the electrode interphase or doublelayer would be a charge leakage process that corresponds to a potential-dependent Faradaic resistance operating in parallel across the double-layer capacitance; its value increasing with declining potential. This case results in a functional form of the self-discharge voltage represented by $V_{i}-V(t) \propto \ln (t+$ const.), i.e. the voltage of the capacitor declines logarithmically with time. ${ }^{5,6}$ Case (2) is when the capacitor electrode material and/or its electrolyte contain impurities that are oxidizable or reducible over the potential range corresponding to the potential difference attained in the capacitor. If these impurities are present in small concentrations then the self-discharge redox process(es) is (are) diffusioncontrolled. This (these) process(es) generally lead ${ }^{5,6}$ to a functional form for the decrease in the capacitor potential having the form $V_{i}-V(t) \propto t^{1 / 2}$. For Case (3), if the self-discharge arises from an ohmic leakage between the pair of double-layer electrodes constituting one cell of the capacitor, the self-discharge is simply that of a decline in voltage of a parallel RC circuit so that the time dependent behavior of the capacitor's voltage would be of the form $\ln \left[V(t) / V_{i}\right]=-t / R C$ or, $V(t)=V_{i} \exp (-t / R C)$. Thus, $V(t)$ declines exponentially with time. ${ }^{5,6}$ In order to acquire a feeling for how these models account for the observed data we have attempted to fit the self-discharge data for capacitors \#1142 and \#1023. Shown in Figure 15 is the best fit to the Case (3) model in the form of an exponential time dependence of $V(t)$ for the entire range self-discharge data for these two capacitors. The best regression analysis fit is shown by the dashed lines and the corresponding expression and a value for the quality of fit given by the $\mathrm{R}^{2}$ value. The shapes of the trend lines do not really correspond to the data 
curves; perhaps if this form of the time dependence was applied only over limited ranges of the data, better fits with multiple time constants could be obtained. Similarly, in Figure 16 the Case (2) model is applied to the data in the form of a logarithmic time dependence of the self-discharge data. There perhaps may be certain time regions of the voltage vs. time data over which a linear fit could be obtained, but certainly the major portions of the data do not correspond to this model. Figure 17 plots the self-discharge data in form of a $\sim t^{1 / 2}$ time dependence for the capacitor voltage. Once again the regression fits to the entire selfdischarge data set is not very good. Perhaps as more capacitor self-discharge data is acquired and analyzed by these and additional model predictions concerning the time dependence of the self-discharge voltage, a better understanding of this important phenomenon will be obtained.

Ten SAFT America, Inc. non-aqueous, carbon-based capacitors rated from $40 \mathrm{~F}$ to $62 \mathrm{~F}$ were delivered and tested. The device dimensions are $1.83 \mathrm{~cm}$ dia. $\times 6.48 \mathrm{~cm}$ high (volume $=0.0171$ liter). The measured capacitances varied from $46 \mathrm{~F}$ to $61 \mathrm{~F}$ at a constantcurrent discharge of $1 \mathrm{~A}$ decreasing to $25 \mathrm{~F}$ to $49 \mathrm{~F}$ at a constant-current discharge of $7 \mathrm{~A}$. The measured ESR values varied from 32 milliohms to 62 milliohms at 1 A constant-current discharges and generally decreased in a non-linear manner to values ranging from 7 milliohms to 24 milliohms at a $7 \mathrm{~A}$ discharge. The specific energies and powers are plotted in Figure 18 along with the values determined for the Maxwell capacitor sets described above.

Three prototype $1 \mathrm{~V}$, carbon-based/aqueous capacitors rated at $26.0 \mathrm{~F}, 14 \mathrm{~F}$ and $7.7 \mathrm{~F}$ were delivered for testing by Federal Fabrics-Fibers. The cells are all $9.5 \mathrm{~cm}$ in diameter and have a projected cross sectional area of $70 \mathrm{~cm}^{2}$ and weighed $0.039 \mathrm{~kg}, 0.037 \mathrm{~kg}$ and $0.038 \mathrm{~kg}$ respectively. The $26.0 \mathrm{~F}$ rated device was measured to have a capacitance of $9.3 \mathrm{~F}$ at a 50 $\mathrm{mA}$ constant-current discharge that decreased to $4.4 \mathrm{~F}$ at $400 \mathrm{~mA}$. Its ESR values were 1.06 ohms at a discharge current of $50 \mathrm{~mA}$ that decreased to $0.45 \mathrm{ohms}$ at $400 \mathrm{~mA}$. The $14 \mathrm{~F}$ rated device had a measured capacitance of $13.2 \mathrm{~F}$ at $50 \mathrm{~mA}$ decreasing to $8.0 \mathrm{~F}$ at $800 \mathrm{~mA}$. The corresponding ESR values for these constant currents were $0.50 \mathrm{ohms}$ and $0.24 \mathrm{ohms}$, respectively. The third capacitor, $7.7 \mathrm{~F}$, had a measured capacitance $7.9 \mathrm{~F}$ at a $50 \mathrm{~mA}$ constant-current discharge decreasing to $6.3 \mathrm{~F}$ at $800 \mathrm{~mA}$. Its measured ESR values were $0.35 \mathrm{ohms}$ and $0.13 \mathrm{ohm}$, respectively, at these same constant-current discharges. The specific energy and power values were measured for all three capacitors and are plotted in Figure 18 for comparison with the other capacitor sets.

Five highly experimental aqueous and non-aqueous electrolyte, $\mathrm{NiO} / \mathrm{Ni}$ compositethin-film electrode capacitors prepared at the University of Wisconsin-Madison were received and tested. These capacitors are single cell devices generally rated at $\sim 1 \mathrm{~F}$ or less. These capacitors displayed highly nonlinear discharge voltage as a function of discharge time during constant-current testing suggesting that the capacitance and/or resistance is dependent on the device operating voltage. Their ESR values were very high, in the several tens of ohms range. The measured specific energy and power are presented in Figure 18 and are considerably lower than the other capacitors tested, but their unrefined packaging burden significantly affected these test results.

\section{Acknowledgment}

This work was supported by the U.S. Department of Energy, Assistant Secretary for Energy Efficiency and Renewable Energy (EE), under DOE Idaho Operations Office Contract DE-AC07-94ID13223.

The authors would also like to thank Pat Smith of the INEEL for editorial and publication assistance. 


\section{References}

1. Office of Transportation Technologies, Energy Efficiency and Renewable Energy, U.S. Department of Energy, Ultracapacitor Program Plan, (1994).

2. A. F. Burke, J. E. Hardin, and E. J. Dowgiallo, "Applications of Ultracapacitors in Electric Vehicle Propulsion Systems," Proceedings of the 34th Power Sources Symposium, Cherry Hill, NJ (1990).

3. J. R. Miller and A. F. Burke, Electric Vehicle Capacitor Test Procedures Manual, Revision, DOE/ID-10491 (October, 1994).

4. C. J. Farahmandi, J. Dispennette, and E. Blank, "High Power 2,300 Farad Ultracapacitors Based on Aluminum/Carbon Electrode Technology,"Proceedings of the Symposium on Electrochemical Capacitors, F. M. Delnick and M. Tomkiewicz, eds., Proceedings Volume 95-29 (The Electrochemical Society, Inc., Pennington, NJ), p. 187.

5. B. E. Conway and J. R. Miller, "Fundamentals and Applications of Electrochemical Capacitors," manual for an Electrochemical Society Short Course, May 4, 1997, ChapterVIII.

6. B. E. Conway, T-C Liu, and W. G. Pell, "Experimental Evaluation and Interpretation of Self-Discharge and Recovery Behavior of $\mathrm{RuO}_{2}$ and Carbon Electrodes," Proceedings of the 6th International Seminal on Double Layer Capacitors and Similar Energy Storage Devices, December 9-11, 1996, Volume 6.

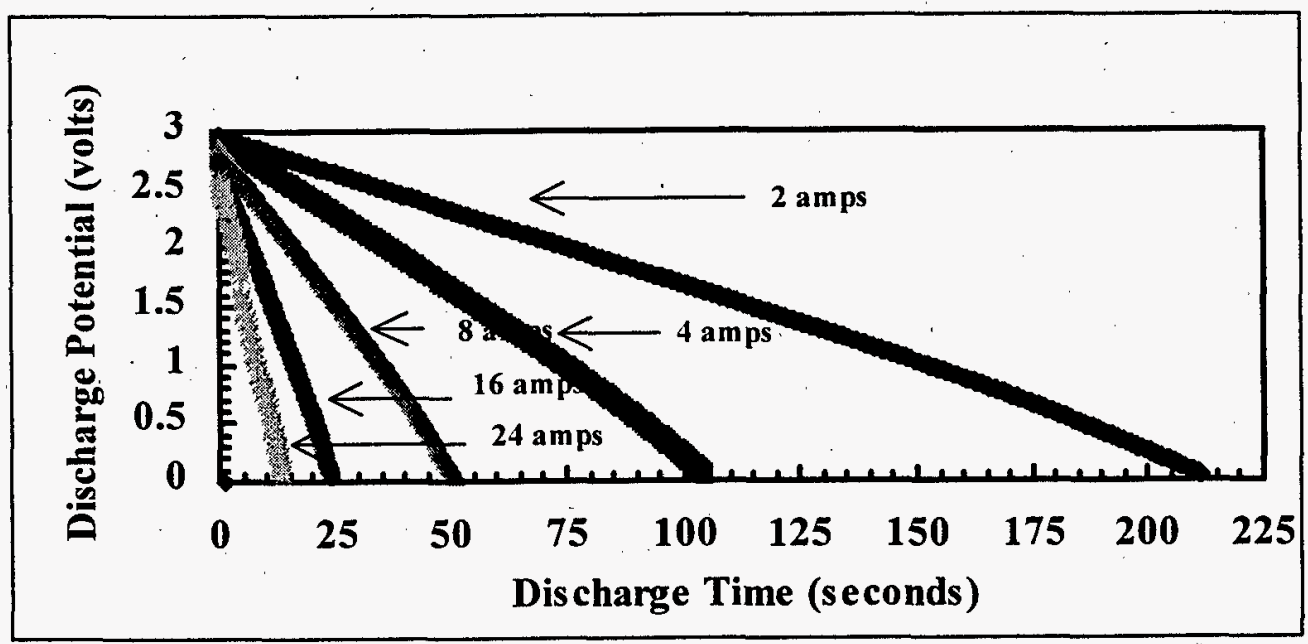

Figure 1.

Data from constant-current tests of Maxwell Capacitor \#1143 


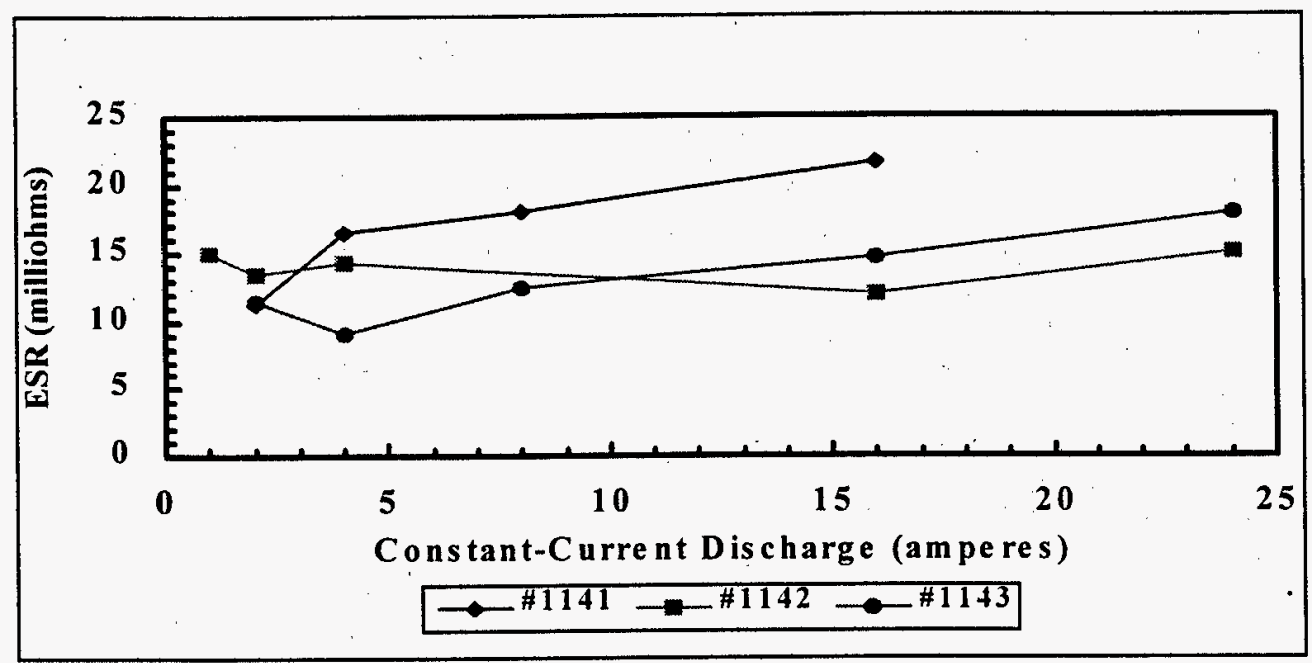

Figure 2.

ESR data calculated from constant-current tests on Cap. \# 1141, 1142, \& 1143

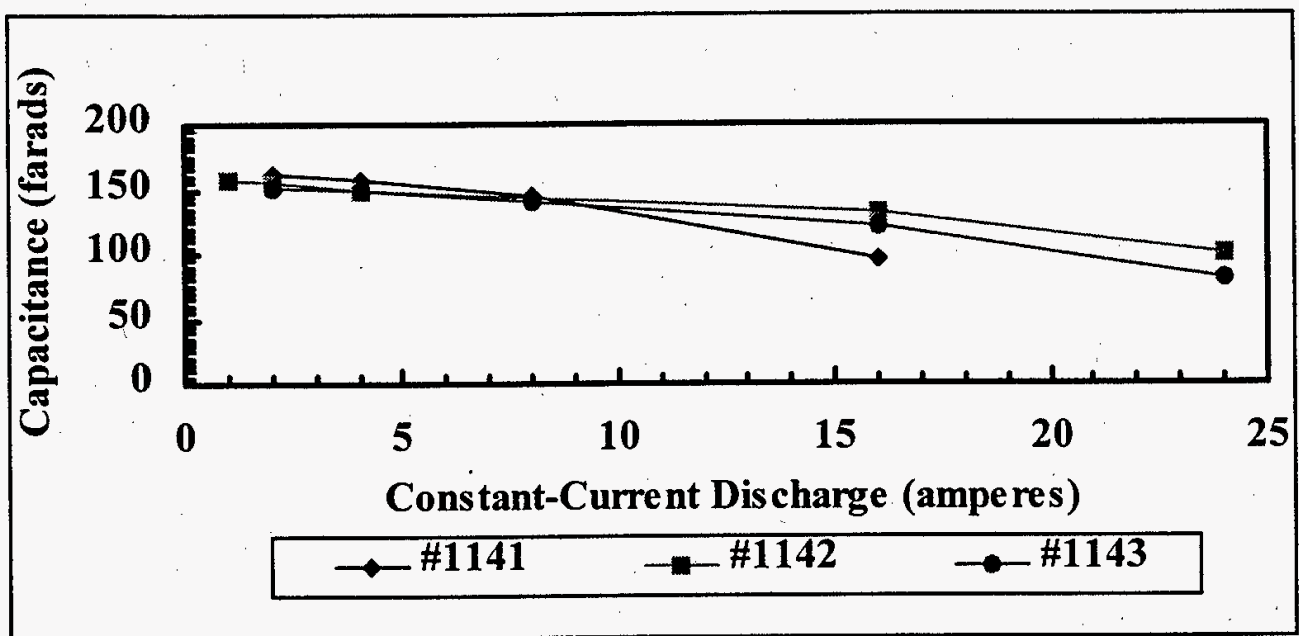

Figure 3.

Capacitance values for capacitors \#1141, \#1142, \#1143 calculated from constant-current tests over a 3 to $1.5 \mathrm{~V}$ discharge range)

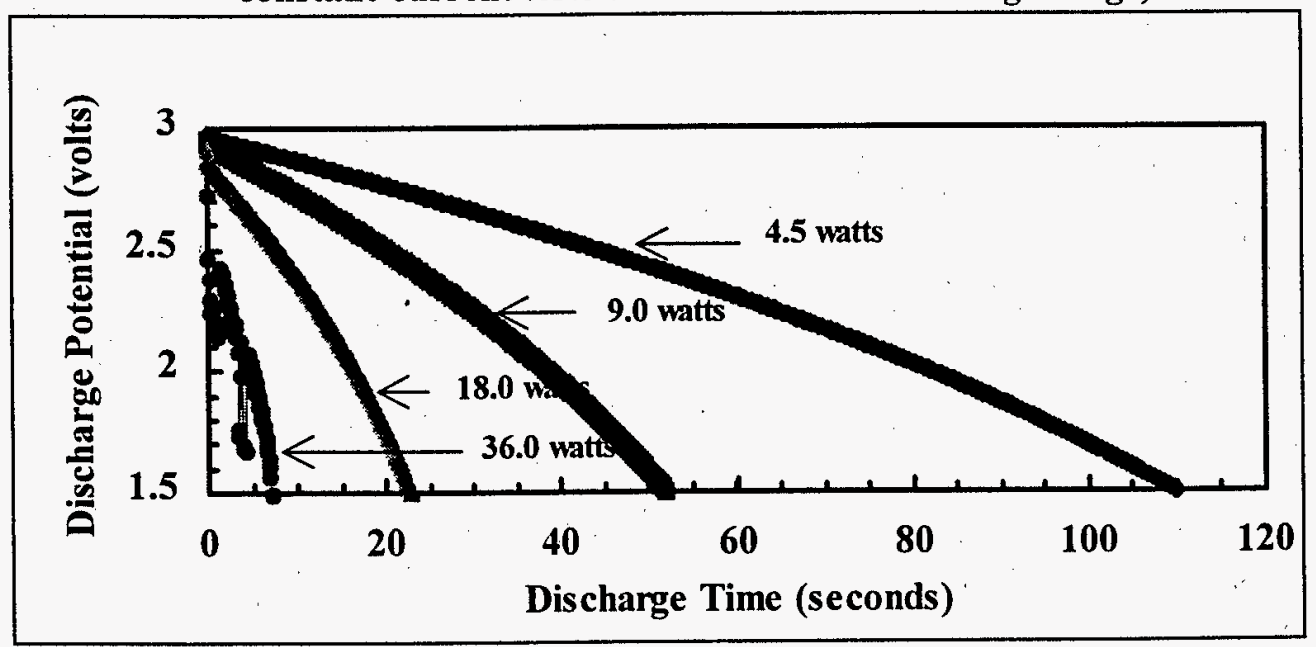

Figure 4.

Data from constant-power test for Maxwell capacitor \#1143 


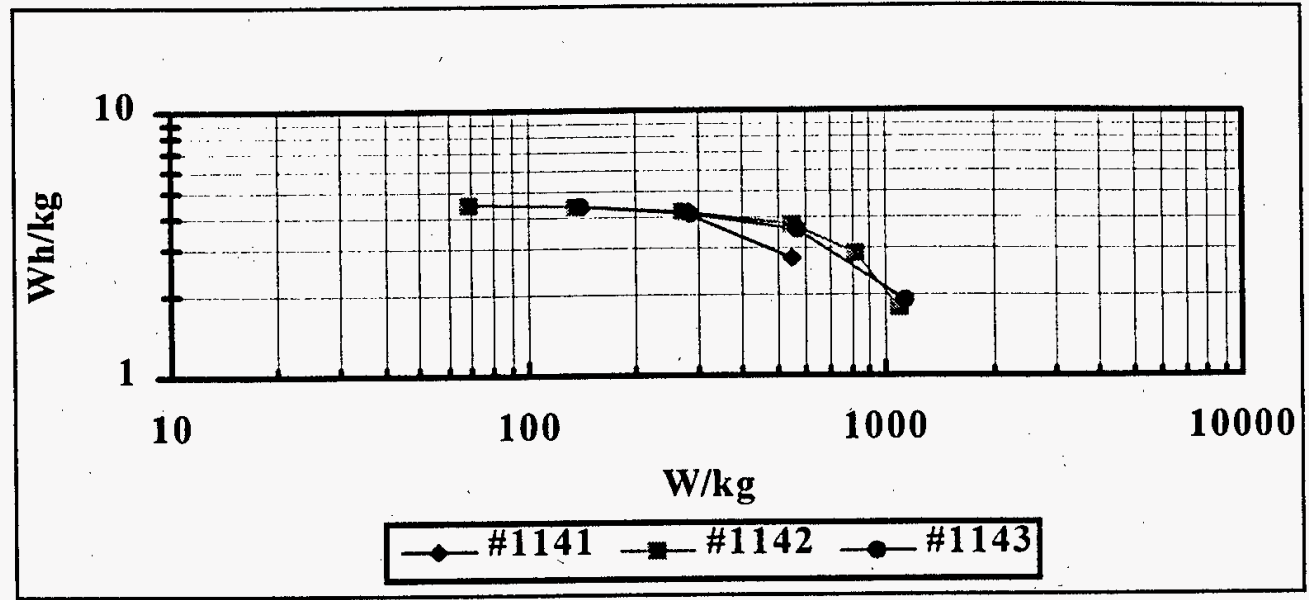

Figure 5.

Ragone plot for constant-power test data ( 3 to $1.5 \mathrm{~V}$ discharge) for Maxwell Capacitors \#1141, 1142 and 1143

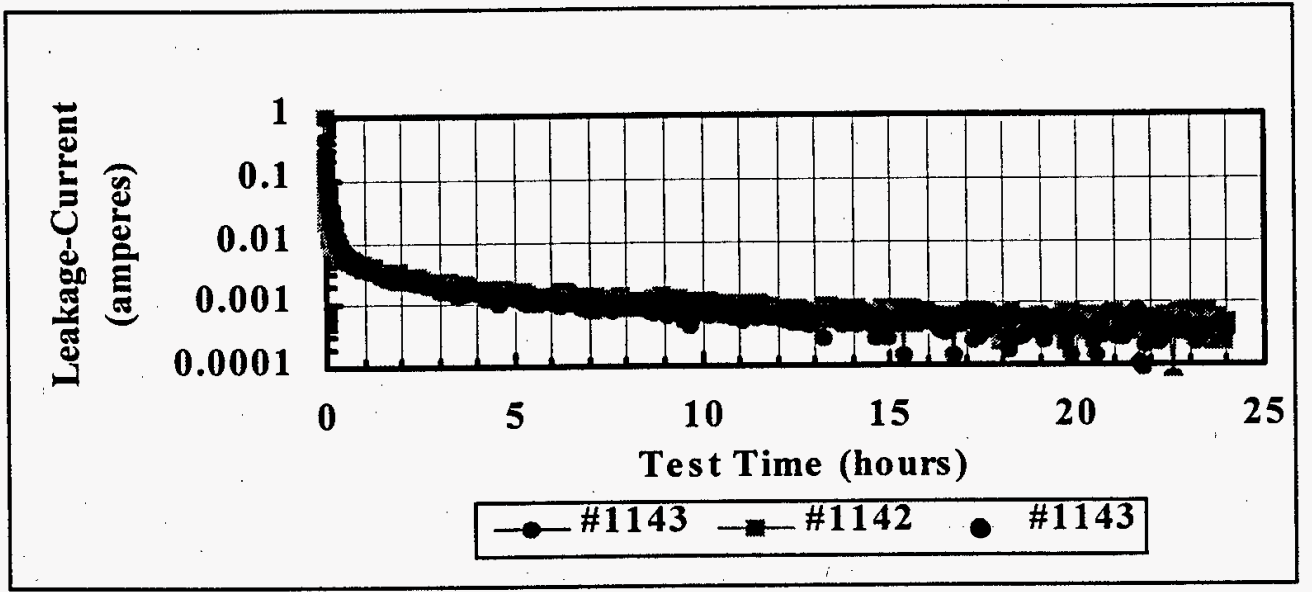

Figure 6.

Data from leakage-current test for Maxwell capacitors \#1142 and \#1143

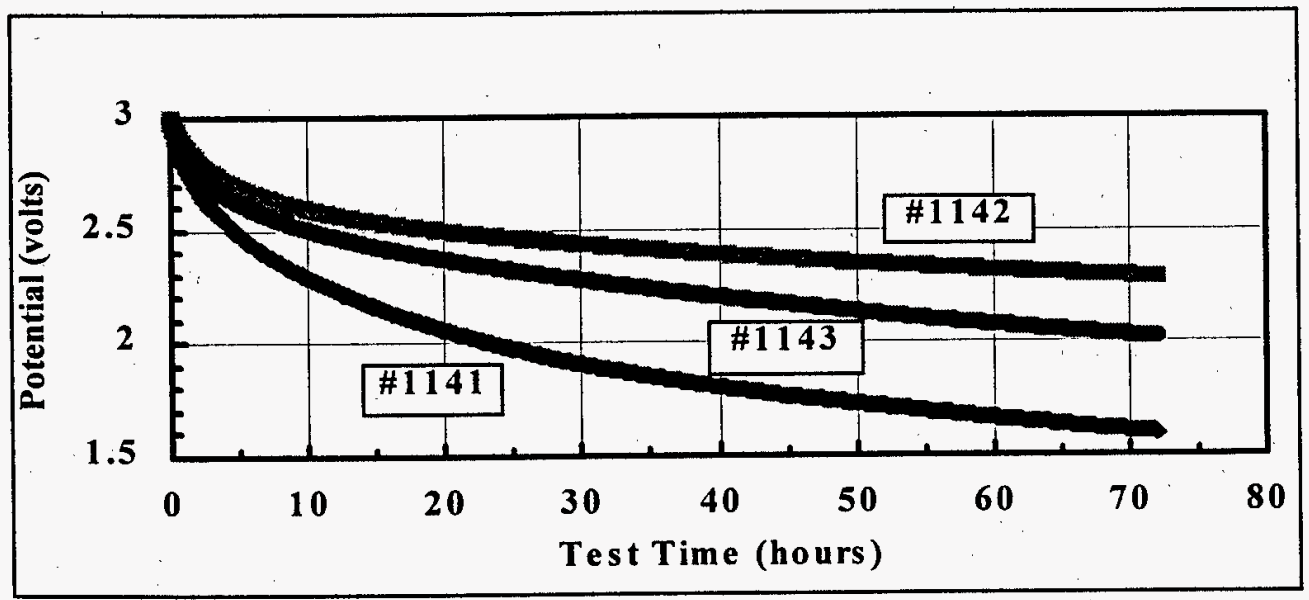

Figure 7.

Data from self-discharge test for Maxwell Cap. \#1141/1142/1143 


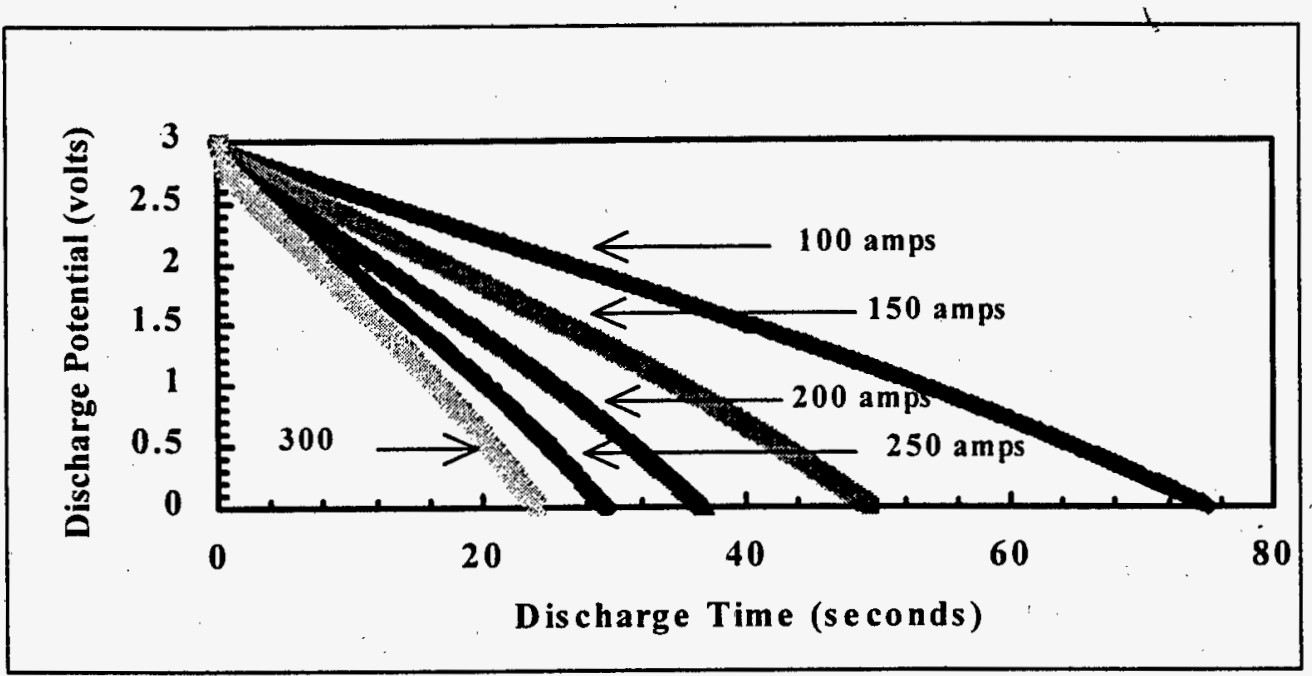

Figure 8.

Data from constant-current tests for Maxwell Clamsell Capacitor \#1023

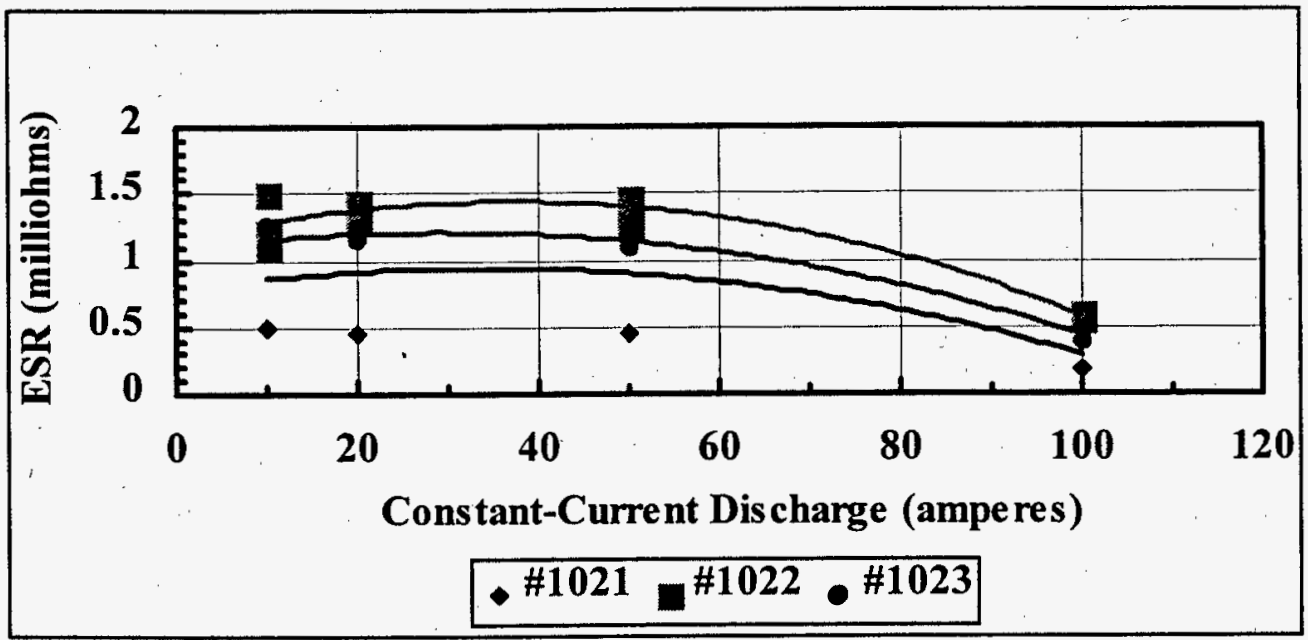

Figure 9.

ESR data calculated from constant-current tests for Clamshell Cap.

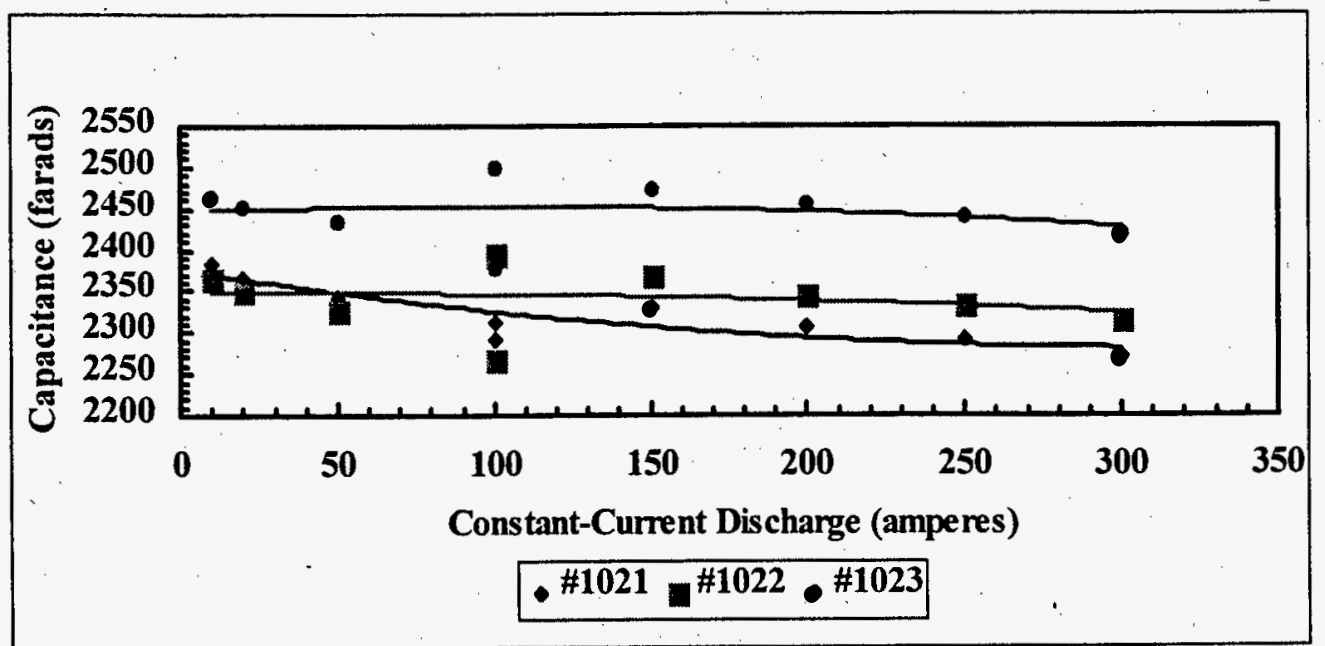

Figure 10.

Capacitance data calculated from constant-current tests ( 3 to $0 \mathrm{~V}$ discharge) for Maxwell Clamshell Capacitors \#1021, \#1022, \& \#1023 


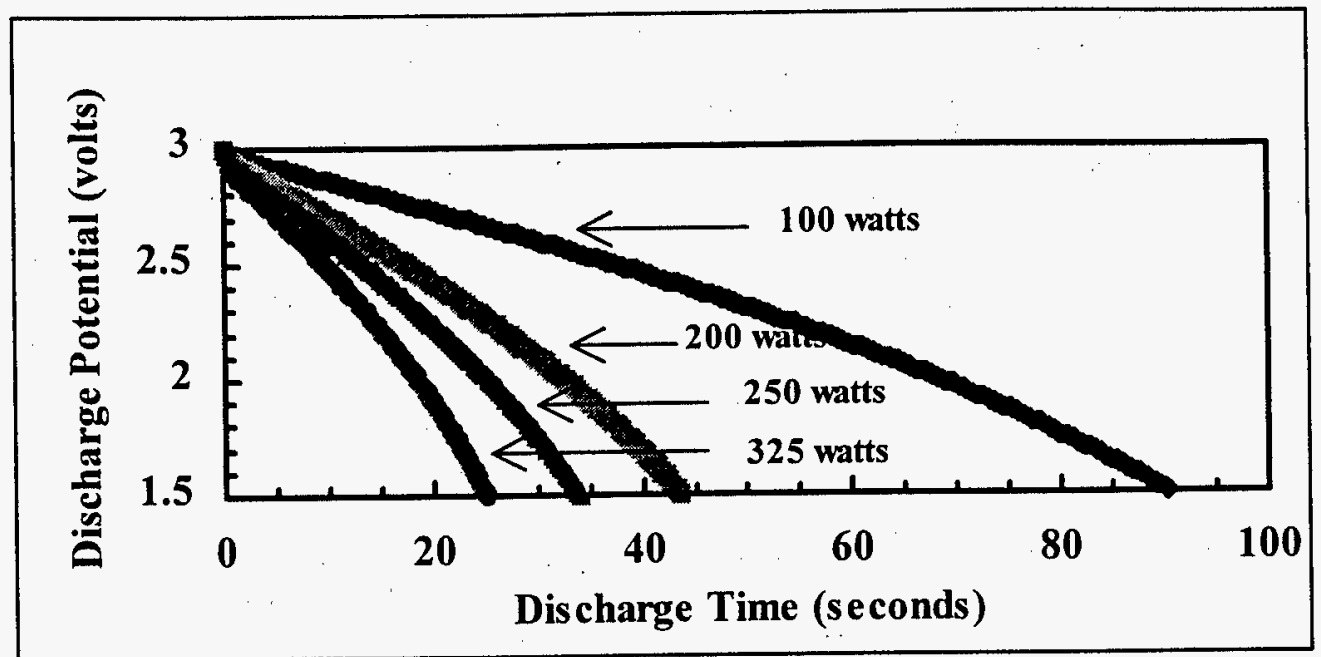

Figure 11.

Data from constant-power tests for Maxwell Clamshell Capacitor \#1023

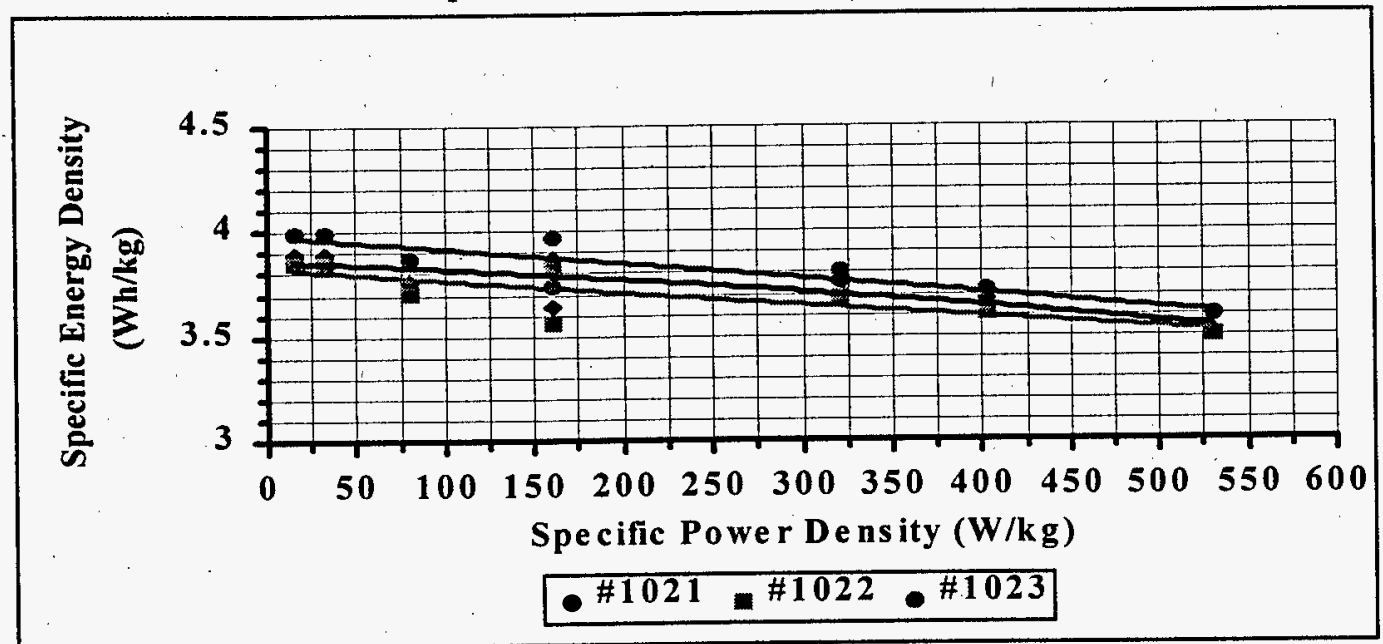

Figure 12.

Ragone plot from constant-power tests ( 3 to $1.5 \mathrm{~V}$ discharge) for Maxwell Clamshell Capacitors \#1021, \#1022, \& \#1023

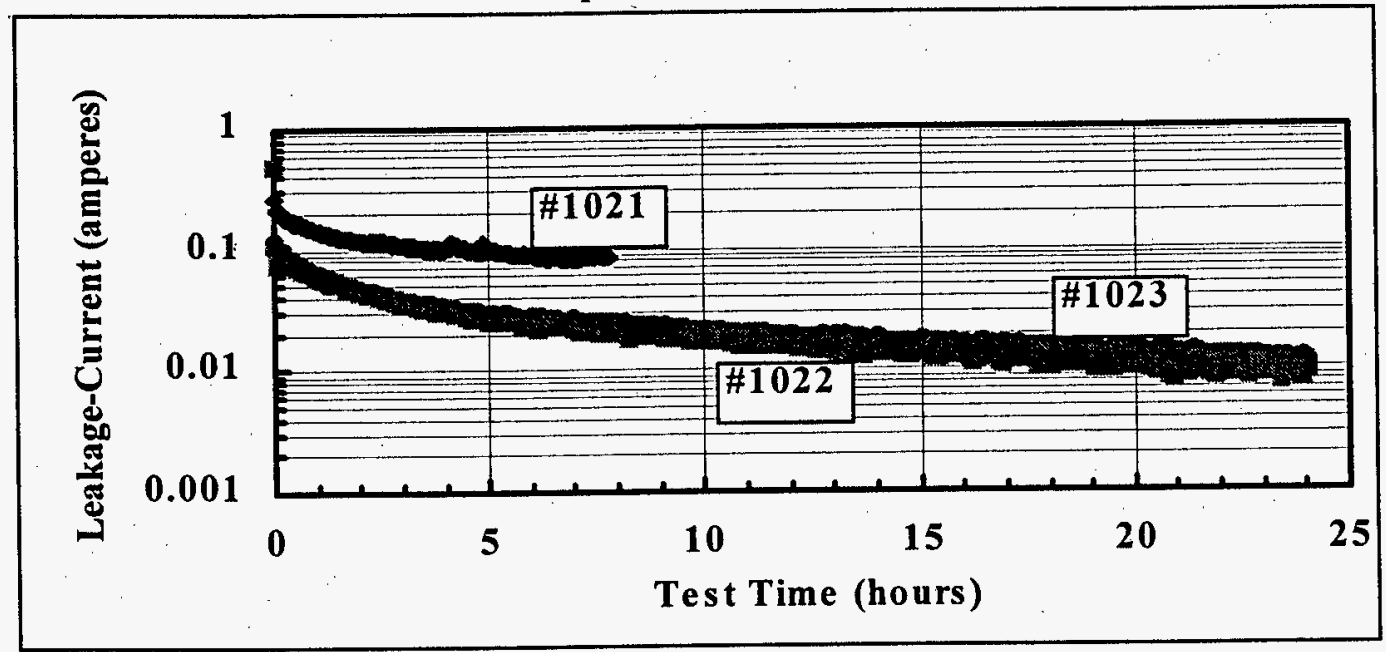

Figure 13.

Data from leakage-current tests for Maxwell Capacitors \#1021, \#1022, \& \#1023 


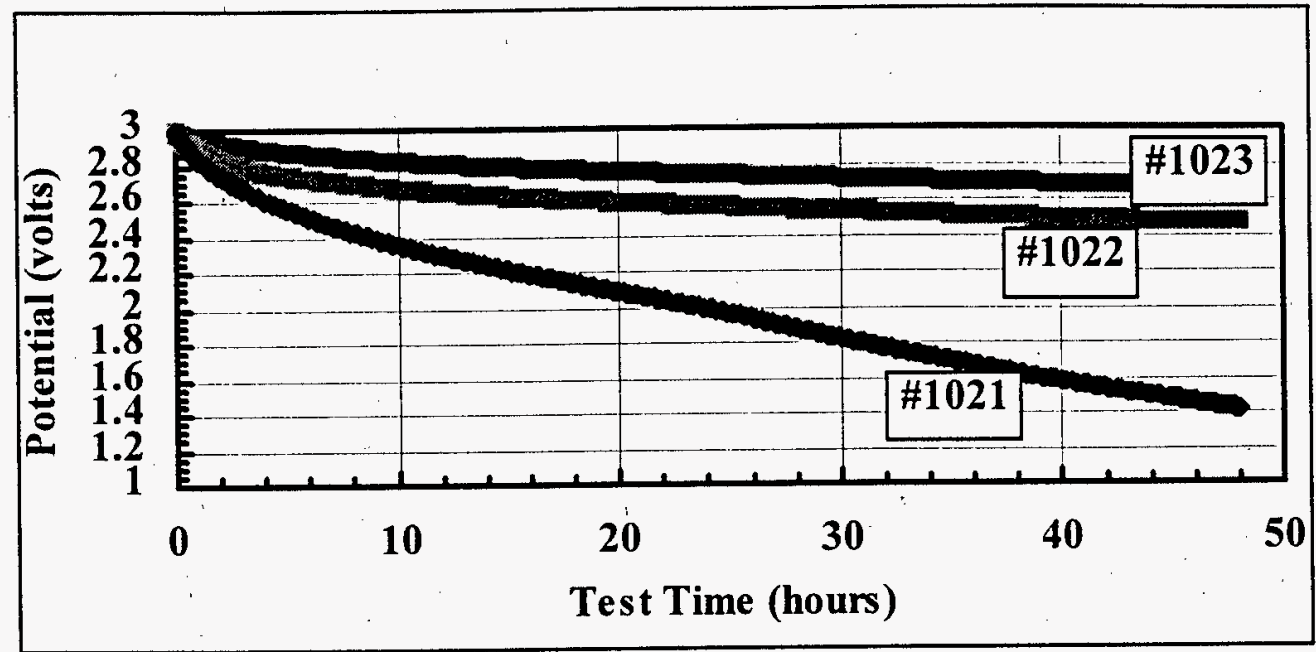

Figure 14.

Data from self-discharge tests for Maxwell Cap. \#1021, \#1022, \& \#1023

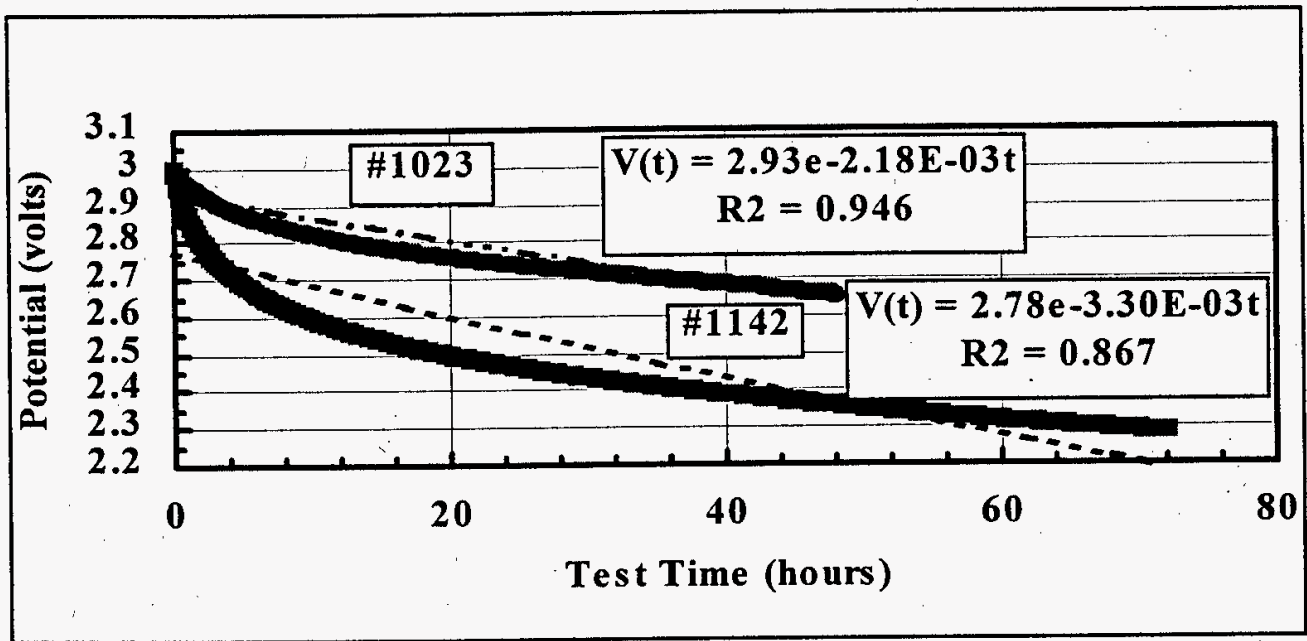

Figure 15.

The case 3 model fit to data from self-discharge tests for Cap. \#1142 \& \#1023

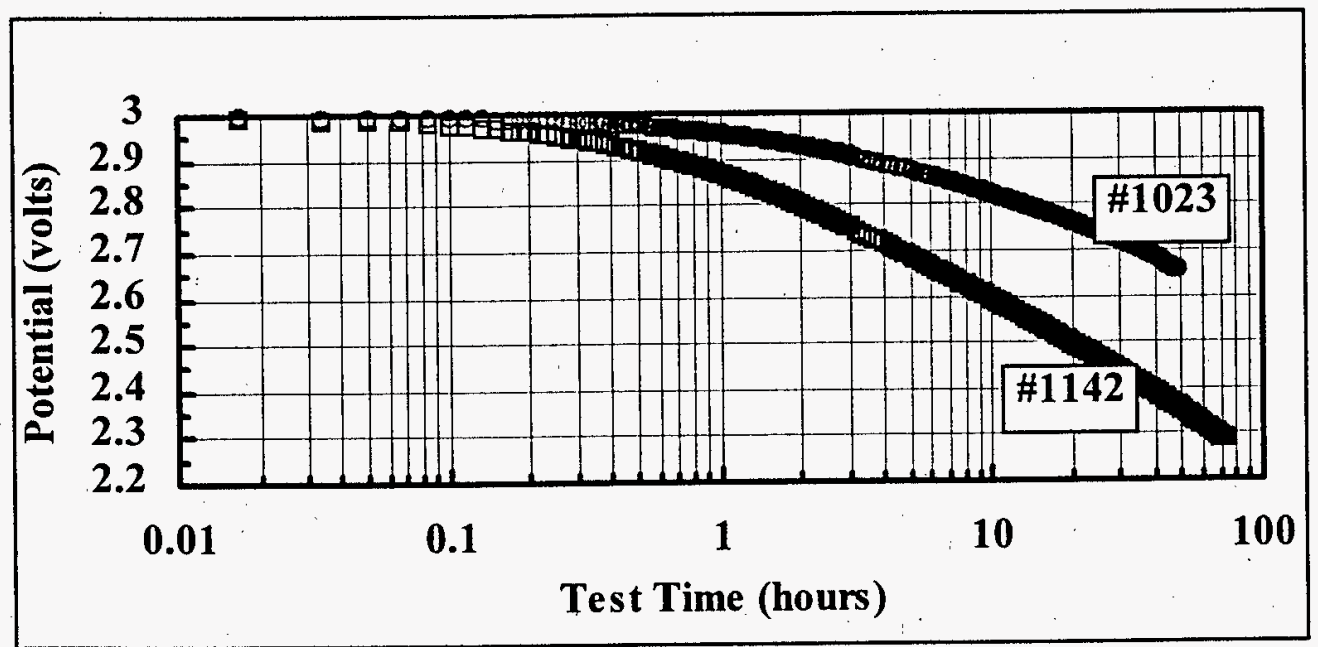

Figure 16.

The case 2 model fit to data from self-discharge tests for Cap. \#1142 \& \#1023 


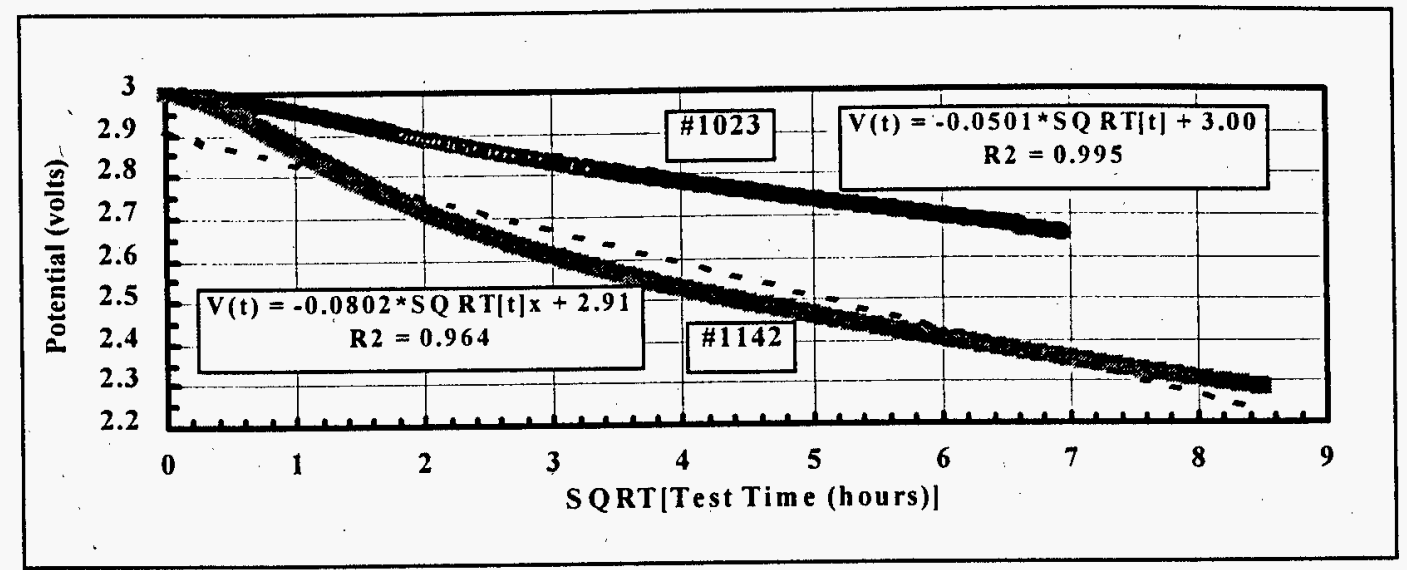

Figure 17.

Self-discharge data for Maxwell Capacitors \#1142 \& \#1023

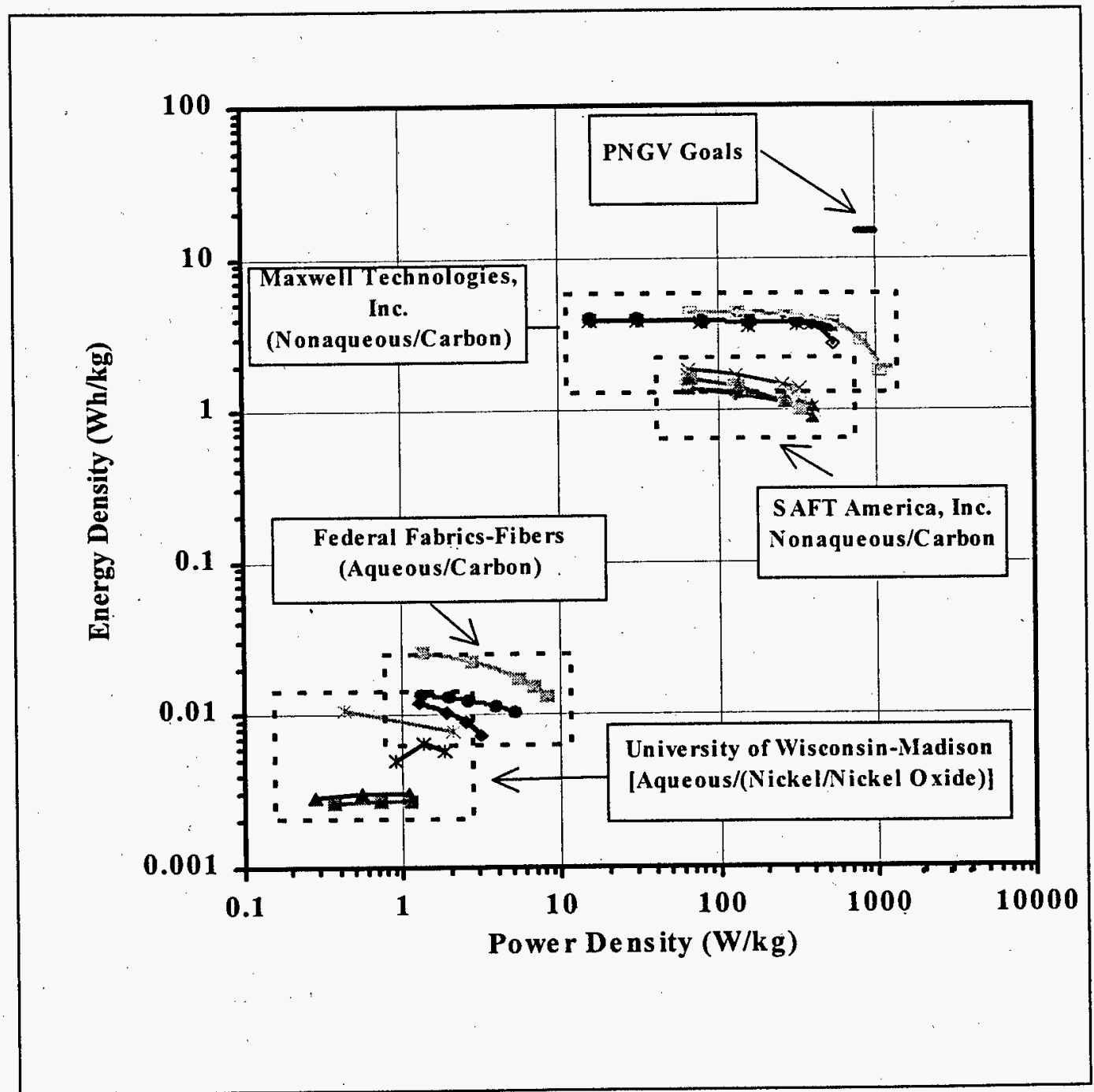

Figure 18.

Ragone plot for capacitors currently under development

(Capacitor weight used for each device was the total as tested weight; discharge voltage range was from the working voltage to $1 / 2$ the working voltage.). 


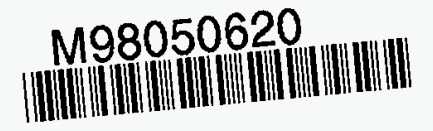

Report Number (14)INEEL/CON--97-01258

$\begin{array}{ll}\text { Publ. Date (11) } & \frac{199711}{D O E / E E, X F} \\ \text { Sponsor Code (18) } & \text { UC-900, DOE/ER } \\ \text { UC Category (19) }\end{array}$

\section{5}

